\title{
Dispersion of sulfur enables sulfur oxidation before iron oxidation in Acidithiobacillus ferrooxidans: A valuable formulation for the genetic engineering toolbox
}

\author{
Yuta Inaba ${ }^{1}$, Timothy Kernan ${ }^{1}$, Alan West $^{1}$, and Scott Banta ${ }^{1}$ \\ ${ }^{1}$ Columbia University
}

March 4, 2021

\begin{abstract}
Acidithiobacillus ferrooxidans are acidophilic chemolithoautotrophs that are commonly reported to exhibit diauxic population growth behavior where ferrous iron is oxidized before elemental sulfur when both are available, despite the higher energy content of sulfur. We have discovered sulfur dispersion formulations that enables sulfur oxidation before ferrous iron oxidation. The oxidation of dispersed sulfur can lower the culture $\mathrm{pH}$ within days below the range where aerobic ferrous iron oxidation can occur so that ferric iron reduction occurs which had previously been reported over extended incubation periods with untreated sulfur. Therefore, we demonstrate that this substrate utilization pattern is strongly dependent on the cell loading in relation to sulfur concentration, sulfur surface hydrophobicity, and the $\mathrm{pH}$ of the culture. Our dispersed sulfur formulation, lig-sulfur, can be used to support the rapid antibiotic selection of plasmid-transformed cells, which is not possible in liquid cultures where ferrous iron is the main source of energy for these acidophiles. Furthermore, we find that media containing lig-sulfur supports higher production of green fluorescent protein (GFP) compared to media containing ferrous iron. The use of dispersed sulfur is a valuable new tool for the development of engineered A. ferrooxidans strains and it provides a new method to control iron and sulfur oxidation behaviors.
\end{abstract}

Dispersion of sulfur enables sulfur oxidation before iron oxidation in Acidithiobacillus ferrooxidans: A valuable formulation for the genetic engineering toolbox

Yuta Inaba, Timothy Kernan, Alan C. West, and Scott Banta*

${ }^{*}$ Department of Chemical Engineering, Columbia University, New York, NY, USA

* Corresponding author.

Mailing address: Department of Chemical Engineering, Columbia University, 820 Mudd MC4721, 500 W. $120^{\text {th }}$ St., New York, NY 10027. Phone: (212) 854-7531, Fax: (212) 854-3054. E-mail: sbanta@columbia.edu

\begin{abstract}
Acidithiobacillus ferrooxidans are acidophilic chemolithoautotrophs that are commonly reported to exhibit diauxic population growth behavior where ferrous iron is oxidized before elemental sulfur when both are available, despite the higher energy content of sulfur. We have discovered sulfur dispersion formulations that enables sulfur oxidation before ferrous iron oxidation. The oxidation of dispersed sulfur can lower the culture $\mathrm{pH}$ within days below the range where aerobic ferrous iron oxidation can occur so that ferric iron reduction occurs which had previously been reported over extended incubation periods with untreated sulfur. Therefore, we demonstrate that this substrate utilization pattern is strongly dependent on the cell loading in relation to sulfur concentration, sulfur surface hydrophobicity, and the $\mathrm{pH}$ of the culture. Our
\end{abstract}


dispersed sulfur formulation, lig-sulfur, can be used to support the rapid antibiotic selection of plasmidtransformed cells, which is not possible in liquid cultures where ferrous iron is the main source of energy for these acidophiles. Furthermore, we find that media containing lig-sulfur supports higher production of green fluorescent protein (GFP) compared to media containing ferrous iron. The use of dispersed sulfur is a valuable new tool for the development of engineered $A$. ferrooxidans strains and it provides a new method to control iron and sulfur oxidation behaviors.

\section{Keywords}

acidophile, sulfur oxidation, iron oxidation, substrate utilization, dispersed sulfur

\section{Introduction}

Bacteria can often utilize multiple energy sources; however, the bioavailability of substrates and constraints on cellular resources leads to myriad of substrate utilization patterns (Chubukov, Gerosa, Kochanowski, \& Sauer, 2014; Monod, 1949; Wong, Gladney, \& Keasling, 1997). Complex regulation networks, influenced by substrate energies and preculture histories, typically drive the mechanisms that lead to diauxic growth or simultaneous substrate consumption behaviors (Narang \& Pilyugin, 2007; Okano, Hermsen, Kochanowski, \& Hwa, 2020). Acidithiobacillus ferrooxidans is a key member of the microbial consortia involved in the industrial-scale bioleaching of copper, and it has been commonly reported to have diauxic behavior on iron and sulfur with a preference for iron oxidation when both sources are present (Beck, 1960; Espejo \& Romero, 1987; Ponce, Moinier, Byrne, Amouric, \& Bonnefoy, 2012; Suzuki, Takeuchi, Yuthasastrakosol, \& Oh, 1990; Wu et al., 2019). However, conflicting behaviors from different strains have been reported for these bacteria, as some of the iron- and sulfur-oxidizing strains studied previously have been phylogenetically reclassified (Amouric, Brochier-Armanet, Johnson, Bonnefoy, \& Hallberg, 2011; Espejo, Escobar, Jedlicki, Uribe, \& Badilla-Ohlbaum, 1988; Falagán \& Johnson, 2016; Ghosh \& Dam, 2009; Hallberg, González-Toril, \& Johnson, 2010; Hedrich \& Johnson, 2013; Kelly \& Wood, 2000; Norris et al., 2020; Ponce et al., 2012; Suzuki et al., 1990; Yarzabal, Appia-Ayme, Ratouchniak, \& Bonnefoy, 2004). Although iron oxidation is generally assumed to precede sulfur oxidation, A. ferrooxidanscells cultivated on ferrous iron have been observed to adsorb to sulfur particles, despite the hydrophobic nature of the surface, and this process can be modeled through a Langmuir equation (Konishi, Takasaka, \& Asai, 1994; Xia et al., 2013). Additionally, the adsorption of $A$. ferrooxidans to sulfur has been found to involve extracellular polymeric substances (EPS) which consist of lipopolysaccharides (Dispirito, Dugan, \& Tuovinen, 1983; Gehrke, Telegdi, Thierry, \& Sand, 1998). Gene expression data in A. ferrooxidans has suggested that genes in both the iron and sulfur pathways can be transcribed and upregulated simultaneously, even when the bacteria are cultivated on ferrous iron (Kucera et al., 2013). The interactions between the sets of enzymes involved in iron and sulfur metabolism are poorly understood, other than the existence of two $\mathrm{bc}_{1}$ complexes allowing for the iron and sulfur oxidation systems to co-exist (Brasseur et al., 2004; Bruscella et al., 2007; Kucera, Sedo, et al., 2016; Valdes et al., 2008). Thus, despite the critical importance of these microorganisms in industrial metal bioleaching operations, gaps still remain in the fundamental understanding of the chemolithotrophic behavior of these bacteria.

The metabolic oxidation of sulfur can be challenging as it requires interfacial interactions that require treatment from the cells. Previous attempts to introduce surfactants to improve the contact between acidophiles and the hydrophobic surface of sulfur yielded only small increases in the oxidation rates of sulfur, and high concentrations of these surfactants inhibited cell growth (Frederick, Jones, \& Starkey, 1956; Knickerbocker, Nordstrom, \& Southam, 2000; Peng, Liu, Nie, \& Xia, 2012). Although the production of EPS specific to sulfur and other proteins by A. ferrooxidans is known to be necessary for the processing of sulfur into a bioavailable form for oxidation, a method to significantly enhance sulfur oxidation with these microorganisms has proven to be elusive (Gehrke et al., 1998; He et al., 2011). Specifically, the identification of the minimum components necessary for the activation of sulfur remain unresolved (Ramirez, Guiliani, Valenzuela, Beard, \& Jerez, 2004). As such, little is known about the consequences of the discrepancy in bioavailability between the soluble ferrous iron and hydrophobic sulfur particles. Given that the oxidation of sulfur involves more favorable reduction potentials for generating reducing equivalents in the cell than using ferrous iron, we sought to address the hypothesis that $A$. ferrooxidans may actually consume sulfur preferentially to ferrous 
iron oxidation under certain conditions (Bird, Bonnefoy, \& Newman, 2011; Quatrini et al., 2009).

The high concentrations of iron present in acidic growth media formulations presents a challenge for genetic studies with $A$. ferrooxidans. Although kanamycin and streptomycin are unstable, they have been used as selectable transformation markers as they provide acceptable selective pressure in Acidithiobacillus family for fundamental genetic work (Inaba, Banerjee, Kernan, \& Banta, 2018; Kernan et al., 2016; Peng, Yan, \& Bao, 1994; Wang et al., 2012; Yu, Liu, Wang, Li, \& Lin, 2014). While the limitations and instability of these selective pressures have been shown for sulfur medium for Acidithiobacillus caldus cultures, the lack of growth inhibition in iron medium has not been measured in liquid cultures with A. ferrooxidans (Wang et al., 2017). Moreover, despite the relative stability of incompatibility group Q (IncQ) plasmids without antibiotics, methods for plasmid maintenance in transconjugant strains beyond replating strains onto selective solid plates have not been explored (Liu, Borne, Ratouchniak, \& Bonnefoy, 2001). Additional development of various techniques and media to improve the ease of genetic engineering is a goal in A. ferrooxidans to be used in applications such as commercial biomining (Gumulya et al., 2018).

Here, we explore the effects of concentrations of iron and sulfur, cell density, and the physical properties of sulfur on the apparent substrate utilization preference of $A$. ferrooxidans ATCC 23270 . We created a simple dispersion formulation of sulfur that shortens the lag time for sulfur consumption. By using this dispersed sulfur, we find that the phenotypes associated with sulfur oxidation are observed more quickly than when using untreated sulfur. Notably, we demonstrate that sulfur oxidation can precede iron oxidation when the sulfur is in this bioavailable form, even at low sulfur concentrations where unformulated sulfur had little impact on ferrous iron oxidation. This formulation mimics the activation of sulfur by cellular material and debris under natural conditions. Furthermore, we demonstrate that this dispersed sulfur allows maintenance of engineered strains in liquid media and that improved growth on elemental sulfur benefits expression of GFP within A. ferrooxidans. Thus, the application of this new bioavailable sulfur formulation opens a new avenue for working with engineered $A$. ferrooxidans and controlling iron and sulfur oxidation.

\section{Materials and Methods}

\section{Reagents and preparation of sulfur}

Unless otherwise noted, all chemicals were purchased from Sigma-Aldrich. Sucrose palmitate was from Alfa Aesar. SYBR Green I nucleic acid was from Molecular Probes. Colloidal sulfur referred to as c-sulfur (Sulfur, 13825 Lot \#MKCC3309), and dispersed colloidal sulfur referred to as d-sulfur (Sulfur, 13825 Lot \#SZBB0320VV) were the sources of sulfur used in this study.

For making defined formulations of dispersed sulfur, colloidal sulfur (c-sulfur) was used. The dispersants used were Tween 20, poly-(sodium 4-styrenesulfonate), sodium 2-naphthalenesulfonate, sucrose palmitate, lignosulfonic acid calcium salt. To prepare the 33.3 weigh by weight percent (wt \%) dispersed sulfur, $1.00 \mathrm{~g}$ of colloidal sulfur and $0.50 \mathrm{~g}$ of the dispersant were added to $25 \mathrm{~mL}$ of $\mathrm{ddH}_{2} \mathrm{O}$ and allowed to equilibrate for $24 \mathrm{~h}$. Another $25 \mathrm{~mL}$ of $\mathrm{ddH}_{2} \mathrm{O}$ was added at $24 \mathrm{~h}$ and mixed for another $24 \mathrm{~h}$ for a total of $48 \mathrm{~h}$. The mixture was centrifuged at $5,000 \mathrm{x}$ g for 3 minutes. The supernatant was removed and the dispersed sulfur was resuspended in $5 \mathrm{~mL}$ of $\mathrm{ddH}_{2} \mathrm{O}$ and allowed to dry at $37{ }^{\circ} \mathrm{C}$ overnight. The dried dispersed sulfur was crushed into a fine powder and rehydrated in appropriate media for use. To prepare the $20 \mathrm{wt} \%$ dispersed sulfur, $0.25 \mathrm{~g}$ of the dispersant was added instead with the same procedures above. Dispersed sulfur made with $20 \mathrm{wt} \%$ lignosulfonic acid calcium salt is referred to as lig-sulfur in this study.

For making dispersed sulfur using the cell lysate of $A$. ferrooxidans, $1 \mathrm{~mL}$ of an $\mathrm{OD}_{600}$ (optical density at $600 \mathrm{~nm}$ ) 10.0 suspension of cells was sonicated on ice water for 5 minutes using a 3 second repeating pulse at a power of $4.5 \mathrm{~W}$ in a Misonix Sonicator 3000. Instead of adding a chemical dispersant, the cell lysate solution was added to $0.30 \mathrm{~g}$ of colloidal sulfur for dispersion in $25 \mathrm{~mL}$ of $\mathrm{ddH}_{2} \mathrm{O}$. The same steps above for dispersing sulfur were followed for the remainder of the protocol.

\section{Bacterial strains, media, and growth conditions}

Acidithiobacillus ferrooxidans ATCC 23270 was obtained from ATCC. The GFP expressing AF-GFP strain 
was derived from the type strain as described previously (Kernan et al., 2016). A. ferrooxidanscultures were

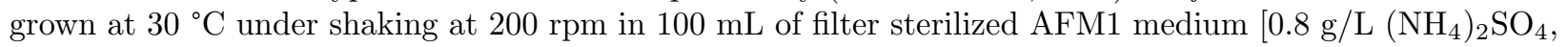
$2.0 \mathrm{~g} / \mathrm{L} \mathrm{MgSO}{ }_{4} \cdot 7 \mathrm{H}_{2} \mathrm{O}, 0.1 \mathrm{~g} / \mathrm{L} \mathrm{K}_{2} \mathrm{HPO}_{4}, 5 \mathrm{~mL} / \mathrm{L}$ trace mineral solution (MD-TMS) and $20.0 \mathrm{~g} / \mathrm{L}(72 \mathrm{mM})$ $\mathrm{FeSO}_{4} \cdot 7 \mathrm{H}_{2} \mathrm{O}$ ] adjusted to $\mathrm{pH} 1.8$ using concentrated sulfuric acid. For variants of AFM1 medium containing different concentrations of ferrous iron, the amount of $\mathrm{FeSO}_{4} \cdot 7 \mathrm{H}_{2} \mathrm{O}$ was changed appropriately. For the medium variant containing no iron, ferrous sulfate was completely omitted, and MD-TMS solution prepared without $\mathrm{FeSO}_{4} \cdot 7 \mathrm{H}_{2} \mathrm{O}$ was used. For the medium variant containing ferric iron instead of ferrous iron, $72 \mathrm{mM}$ ferric iron was added using ferric sulfate hydrate. The different sulfur preparations were added at the noted concentrations to each culture before incubation using aseptic techniques. Both strains were maintained throughout the experiments by weekly sub-culture into AFM1 medium without any addition of sulfur. Cells were harvested by centrifugation and washed with AFM1 basal salts (AFM1 medium without ferrous sulfate).

\section{Measurements of culture conditions}

The $\mathrm{pH}$ of the culture was measured using an Oakton $\mathrm{pH} 700$ meter. The concentration of ferrous iron in solution was measured by titrating $1 \mathrm{~mL}$ of the medium with $10 \mu \mathrm{L}$ of ferroin indicator with $0.1 \mathrm{M}$ cerium (IV) sulfate until the color of the indicator changed from orange-red to a light blue. The samples were diluted with $\mathrm{ddH}_{2} \mathrm{O}$ adjusted to $\mathrm{pH} 1.8$ as necessary so that titrated ferrous iron was below the equivalent of $30 \mathrm{mM}$ ferrous iron.

\section{Measurements of cell density by spectrophotometry}

A $1 \mathrm{~mL}$ sample of culture was centrifuged at $3,000 \times \mathrm{g}$ for 10 seconds to separate sulfur from the solution. The remaining solution was then centrifuged at $17,000 \times \mathrm{g}$ for 1 minute to pellet cells. The supernatant was removed, and the cells were resuspended in $1 \mathrm{~mL}$ of $5 \mathrm{mM}$ Tris- $\mathrm{HCl}$, adjusted to $\mathrm{pH} 8.5$. The suspended cells were incubated at $95{ }^{\circ} \mathrm{C}$ for 10 minutes. In a 96 -well plate, $200 \mu \mathrm{L}$ of the cell solution was added to 50 $\mu \mathrm{L}$ of a $5 \times$ SYBR Green I solution diluted with $5 \mathrm{mM}$ Tris- $\mathrm{HCl}$ and incubated at room temperature for 10 minutes. The fluorescence was measured at an excitation wavelength of $497 \mathrm{~nm}$ and an emission wavelength $520 \mathrm{~nm}$ using a Molecular Devices SpectraMax M2 spectrophotometer after a background subtraction using

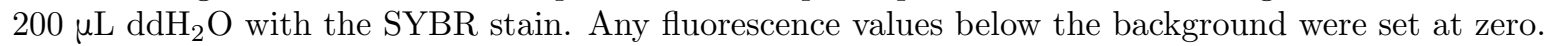

The fluorescence measurements were converted to $\mathrm{OD}_{600}$ measurements using a power function regressing known $\mathrm{OD}_{600}$ concentrations of $A$. ferrooxidanssuspensions with the above protocol (Fig. S1).

\section{GFP selection assay}

Suspensions of AF-GFP and WT strains were washed with AFM1 basal salts and adjusted to $\mathrm{OD}_{600}$ of 1.0. The suspensions of the two strains were mixed to obtain AF-GFP suspensions diluted with WT at a ratio of 1 to 100. The pure AF-GFP strain and the diluted suspensions were incubated using an initial $\mathrm{OD}_{600}$ of 0.005 in $5 \mathrm{~mL}$ cultures of four different media: AFM1 with $40 \mu \mathrm{g} / \mathrm{mL}$ leucine and $19 \mu \mathrm{g} / \mathrm{mL}$ diaminopimelic acid; AFM1 with $40 \mu \mathrm{g} / \mathrm{mL}$ leucine, $19 \mu \mathrm{g} / \mathrm{mL}$ diaminopimelic acid, and $250 \mu \mathrm{g} / \mathrm{mL}$ kanamycin sulfate (AFM1K); LSM4 $\left[0.8 \mathrm{~g} / \mathrm{L}\left(\mathrm{NH}_{4}\right)_{2} \mathrm{SO}_{4}, 2.0 \mathrm{~g} / \mathrm{L} \mathrm{MgSO}_{4} \cdot 7 \mathrm{H}_{2} \mathrm{O}, 0.1 \mathrm{~g} / \mathrm{L} \mathrm{K}_{2} \mathrm{HPO}_{4}, 0.19 \mathrm{~g} / \mathrm{L}\right.$ citric acid, $5 \mathrm{~mL} / \mathrm{L}$ trace mineral solution (MD-TMS), $40 \mu \mathrm{g} / \mathrm{mL}$ leucine, $19 \mu \mathrm{g} / \mathrm{mL}$ diaminopimelic acid, $17.9 \mu \mathrm{g} / \mathrm{mL} \mathrm{Fe} 2\left(\mathrm{SO}_{4}\right)_{3}$, and $1 \mathrm{~g} / \mathrm{L}$ lig-sulfur] adjusted to $\mathrm{pH} 1.8$ using concentrated sulfuric acid with $250 \mu \mathrm{g} / \mathrm{mL}$ kanamycin sulfate; LSM4 adjusted to pH 5.0 using $\mathrm{NaOH}$ pellets with $250 \mu \mathrm{g} / \mathrm{mL}$ kanamycin sulfate. While growth in AFM1 does not require leucine or diaminopimelic acid, these components were added to eliminate them as factors in applying selective pressure. The leucine, diaminopimelic acid, $\mathrm{Fe}_{2}\left(\mathrm{SO}_{4}\right)_{3}$, and kanamycin sulfate components of the media were added to the cultures immediately before incubation to prevent premature degradation and precipitation.

The endpoints of the cultures were determined as complete oxidation of ferrous iron for the AFM1 and AFM1K media and reaching $\mathrm{pH}<1.5$ and $\mathrm{pH}<1.8$ for the LSM4 media adjusted to $\mathrm{pH} 1.8$ and 5.0 respectively. After reaching the endpoint of the first passage for each culture, $50 \mu \mathrm{L}$ of the culture was inoculated into $5 \mathrm{~mL}$ of fresh medium for two more passages. At the end of each passage the remaining cells were harvested by centrifugation and washed in AFM1 basal salts. The cells were resuspended in a 
solution consisting of $250 \mu \mathrm{L}$ modified $2: 2$ basal salts $\left[22.5 \mathrm{~g} / \mathrm{L}\left(\mathrm{NH}_{4}\right)_{2} \mathrm{SO}_{4}, 3.75 \mathrm{~g} / \mathrm{L} \mathrm{MgSO}_{4} \cdot 7 \mathrm{H}_{2} \mathrm{O}\right.$, and $0.75 \mathrm{~g} / \mathrm{L} \mathrm{KCl}]$ and $250 \mu \mathrm{L}$ phosphate buffered saline at $\mathrm{pH} 7.4$ and transferred to a flow cytometry tube. 1 $\mu \mathrm{L}$ of SYTO 61 was added to the tube and the sample was incubated for 15 minutes at room temperature protected from light.

Flow cytometry was conducted using a BD LSRII. All samples were analyzed under identical photomultiplier tube settings: forward scatter $(\mathrm{FSC})=600 \mathrm{~V}$, side scatter $(\mathrm{SSC})=250 \mathrm{~V}$, fluorescein isothiocyanate (FITC) $=450 \mathrm{~V}(\mathrm{GFP})$, allophycocyanin (APC) $=450 \mathrm{~V}$ (SYTO 61). Event detection thresholds were set as follows: $\mathrm{FSC}=500$ and SSC $=200$ RFUs. 50,000 events were collected for each sample. Post-run analysis was conducted using FCS Express 7 software. The gating strategy isolated cells by first gating the forward and side scattering profiles to capture all potential cells and remove debris. Then, these events were further gated using the APC and FITC channels to isolate the population that had the SYTO 61 stain. All events with values of APC and FITC >10 were determined to be either WT or AF-GFP cells (Fig. S2).

\section{Results}

\section{Growth of $A$. ferrooxidans on untreated sulfur and ferrous iron}

We first investigated how the adsorption capacity of the c-sulfur surface affected the population behavior and apparent substrate utilization of $A$. ferrooxidans. These experiments were conducted in the presence of both ferrous iron and elemental sulfur, which are the two energy sources most commonly associated with this species. The microbial oxidation of ferrous iron and sulfur by $A$. ferrooxidansimpacts the $\mathrm{pH}$ of the culture where ferrous iron oxidation is accompanied by an increase in $\mathrm{pH}$ because of proton consumption through oxygen reduction and the oxidation of sulfur results in a decrease in $\mathrm{pH}$ because of sulfuric acid production.

Under a high initial cell density of an optical density at $600 \mathrm{~nm}\left(\mathrm{OD}_{600}\right)$ of 0.05 , corresponding to a cell density of $4.2 \times 10^{8}$ cells $/ \mathrm{mL}$, the oxidation of $72 \mathrm{mM}$ of iron in the medium without untreated colloidal sulfur, referred to as c-sulfur, occurred rapidly, and the consumption of ferrous iron reached completion by $18 \mathrm{~h}$ (Fig. 1A). When $10 \mathrm{~g} / \mathrm{L}$ of c-sulfur was added under the same conditions, the oxidation of ferrous iron reached completion by $24 \mathrm{~h}$, displaying a small but noticeable delay compared to when c-sulfur is not present (Fig. 1A). Despite the oxidation of ferrous iron reaching completion before c-sulfur, the change in $\mathrm{pH}$ associated with the oxidation of the same concentration of iron differed when c-sulfur was added. The average maximum $\mathrm{pH}$ for the three cultures without c-sulfur was $2.20 \pm 0.01$, while the average maximum $\mathrm{pH}$ for the three cultures with c-sulfur was $2.02 \pm 0.01$ (Fig. 1A). When c-sulfur was added, the planktonic cell population in the cultures initially reduced as some of the population adsorbed to the sulfur surface and was not detected. However, the remaining planktonic cells rapidly multiplied in the first $24 \mathrm{~h}$ corresponding to the consumption of the readily available energy obtained from soluble ferrous iron, which requires no complex processing by the cells (Fig. S3). This observation led us to infer that the high density of cells added exceeds the adsorption capacity of the c-sulfur surface and that adsorbed cells did not contribute to iron oxidation as the same total number of cells were added in both conditions. Furthermore, the pH data suggested that $A$. ferrooxidans cells pre-cultured with ferrous iron were capable of simultaneously oxidizing small amounts of c-sulfur to produce sulfuric acid, leading to a lower maximum $\mathrm{pH}$ in culture.

Thus, we studied the population behavior of these cells using an order of magnitude lower initial cell density of $\mathrm{OD}_{600}$ of 0.005 , corresponding to a cell density of $4.2 \times 10^{7}$ cells $/ \mathrm{mL}$. We expected a significant proportion of the inoculated cells to be adsorbed to the surface under these conditions and the apparent lag phase would be extended as more cell divisions would be needed to cover the available surface sites on c-sulfur before planktonic cells became present in appreciable numbers to oxidize ferrous iron. While the cells took longer to consume the ferrous iron without c-sulfur, reaching completion by $34 \mathrm{~h}$, we were surprised to find that the lag phase before iron oxidation was significantly prolonged, taking 120 to $144 \mathrm{~h}$ to reach completion (Fig. 1B). The average maximum $\mathrm{pH}$ for the three cultures without c-sulfur was $2.20 \pm 0.01$, unchanged from that of the high initial cell density condition (Fig. 1B). These data demonstrated that the oxidation of iron dominates the $\mathrm{pH}$ change and was unaffected by the number of cells catalyzing this reaction. The average maximum $\mathrm{pH}$ for the three cultures containing c-sulfur was lower at $1.91 \pm 0.02$, and the slight $\mathrm{pH}$ decrease 
detected before the onset of iron oxidation suggested that some sulfur oxidation prior to iron oxidation occurred (Fig. 1B). A small but non-zero concentration of planktonic cells were detected during the initial incubation period on c-sulfur prior to iron oxidation, which shows the active process of cell adsorption to the particles (Fig. S3). The number of planktonic cells began to rapidly increase at $120 \mathrm{~h}$ when ferrous iron oxidation was detected (Fig. S3).

An initial cell density of $\mathrm{OD}_{600}$ of 0.001 , corresponding to a cell density of $8.3 \times 10^{6}$ cells $/ \mathrm{mL}$, was used to confirm that the lag phase depended primarily on cell loading. Under these conditions, the onset of iron oxidation occurred around $192 \mathrm{~h}$, later than that was observed for the initial $\mathrm{OD}_{600}$ of 0.005 (Fig. $1 \mathrm{C})$. The effect of modulating the ferrous iron concentration on the lag phase in medium containing 10 $\mathrm{g} / \mathrm{L} \mathrm{c}$-sulfur was also evaluated. We found that changing the ferrous concentration from $72 \mathrm{mM}$ to $100 \mu \mathrm{M}$ had small effect on the time taken to reach exponential phase. However, elimination of all ferrous iron for metabolism and trace nutrients prevented A. ferrooxidans from growing (Fig. 1C). The slight acidification of the medium was approximately similar to that for abiotic controls under the same condition corresponding to the slight evaporation of water over time. The concentrations of ferrous iron had pronounced effects on the late exponential phase of growth, particularly as each of the conditions that passed the ferrous iron oxidation threshold of $\mathrm{pH}$ 1.3. The rate of media acidification decreased earliest for cultures with the lowest concentrations of iron, while the cultures with $72 \mathrm{mM}$ of iron more rapidly reached a lower $\mathrm{pH}$ (Fig. 1C). Ferric iron reduction activity below $\mathrm{pH} 1.3$ was also detected as the ferrous iron concentration started to increase as sulfur oxidation continued (Fig. 1C).

Visual changes in the cultures with a starting $\mathrm{OD}_{600}$ of 0.005 were documented at key time points (Fig. 1D). Initially, the hydrophobic c-sulfur phase separates to the air-water boundary and sticks to the glass walls. For the replicate which happened to have the earliest onset of iron oxidation, a dispersed mixture was produced by $96 \mathrm{~h}$ prior to consumption of ferrous iron. At $120 \mathrm{~h}$, when the ferrous iron is depleted, the medium took on the dark orange color of ferric iron which became paler over time as the $\mathrm{pH}$ of the solution decreased. These visible markers were similarly noted for the other two replicates at relevant times, unveiling that iron-adapted $A$. ferrooxidans cells can process c-sulfur into a bioavailable and accessible form without significant iron oxidation.

\section{Sulfur oxidation precedes ferrous iron oxidation with dispersed sulfur}

We serendipitously discovered an alternative sulfur formulation, supplied by a commercial vendor as colloidal sulfur, which surprisingly dispersed readily and evenly upon addition to the media to create a homogenous mixture (Fig. S4). The new formulation, referred to as d-sulfur, enabled A. ferrooxidans to exhibit starkly different consumption patterns for iron and sulfur as compared to c-sulfur even when added at a low concentration of $1.0 \mathrm{~g} / \mathrm{L}$. In cultures with d-sulfur, the $\mathrm{pH}$ of the solution rapidly decreased to a minimum whereas little ferrous iron oxidation occurred. The bulk of the iron oxidation and the associated $\mathrm{pH}$ increase occurred after $36 \mathrm{~h}$ (Fig. 2A). When c-sulfur was used instead at $1.0 \mathrm{~g} / \mathrm{L}$, we observed the commonly recognized behavior of ferrous iron oxidation followed by sulfur oxidation, indicating that the inoculated cells did not all adsorb to the c-sulfur surface (Fig. 2A). These results suggested that the physical properties of d-sulfur were special in allowing A. ferrooxidans to utilize the sulfur quickly, indicating that the observed consumption order was influenced by the hydrophobicity of the sulfur particles.

At higher concentrations of d-sulfur, the time needed for the completion of the ferrous iron oxidation was increasingly prolonged, demonstrating that additional sulfur repressed iron oxidation (Fig. 2B). At the two highest concentrations tested of d-sulfur, $5.0 \mathrm{~g} / \mathrm{L}$ and $10.0 \mathrm{~g} / \mathrm{L}$, ferrous iron concentration initially decreased and then reversed to increasing over the course of hours (Fig. 2B). The media $\mathrm{pH}$ continued to decrease well below the critical $\mathrm{pH}$ of 1.3 , which is suggested to inhibit iron oxidation, reaching a final $\mathrm{pH}$ of $0.73 \pm$ 0.01 and $0.63 \pm 0.01$ at $168 \mathrm{~h}$ respectively, for d-sulfur concentrations of 5.0 and $10.0 \mathrm{~g} / \mathrm{L}$ (Fig. 2B). With the formulated d-sulfur, the reduction of ferric iron was observed quickly than previously reported as the consumption of dispersed sulfur led to the rapid acidification of the media under aerobic conditions.

The color and different physical properties of d-sulfur compared to c-sulfur indicated that it had been 
chemically processed prior to being sold to us by the vendor (Fig. S4). Based on its appearance and properties, we hypothesized that the d-sulfur was a water dispersible granule used in agricultural applications, produced by emulsifying sulfur with a lignosulfonate salt (Eller \& Person, 1969). As the exact composition of the commercial d-sulfur was unknown, we studied several classes of surfactant compounds and developed a simple sulfur formulation to enable the preferential consumption of elemental sulfur prior to ferrous iron oxidation in A. ferrooxidans. Numerous dispersant candidates were tested, including calcium lignosulfonate, other types of sulfonated compounds, a glycolipid, Tween-20, and A. ferrooxidans cell lysate. All of these compounds dispersed the c-sulfur into water, and dry formulated powders were obtained (Fig. S4). The calcium lignosulfonate dispersed sulfur, referred to as lig-sulfur, dispersed into AFM1 medium similarly to d-sulfur, unlike c-sulfur which immediately phase separated after vigorous vortexing with the medium (Fig. S4).

Once these powders were redispersed into AFM1 medium, only a few of the formulations tested displayed altered sulfur utilization behaviors. Little to no growth was detected with sulfur dispersed with sodium naphthalene sulfonate, poly-(sodium 4-styrenesulfonate), and Tween-20 as no media clarification or color changes were observed when added to the media, suggesting that these chemicals were incompatible with A. ferrooxidans. The substrate utilization behavior at $1 \mathrm{~g} / \mathrm{L}$ lig-sulfur in conjunction with iron closely mimicked that of d-sulfur (Fig. 2C). Furthermore, the growth of the cells on $10 \mathrm{~g} / \mathrm{L}$ of lig-sulfur also exhibited the transition from ferrous iron oxidation to ferric iron reduction demonstrating that the formulation we developed induced a similar response from A. ferrooxidans as d-sulfur (Fig. 2C). When the glycolipid sucrose palmitate was used to disperse sulfur, improvements to sulfur oxidation were achieved, but the effects were less pronounced than with the lignosulfonate. Comparison of the 20 (wt \%) sucrose palmitate to the 33.3 wt $\%$ sucrose palmitate dispersed sulfur cultures demonstrated that there is a critical point for dispersion where the dispersed sulfur becomes bioavailable for oxidation by the cells so that sulfur oxidation largely precedes ferrous iron oxidation. The final $\mathrm{pH}$ for the $33.3 \mathrm{wt} \%$ sucrose palmitate sulfur was lower at the end of ferrous iron oxidation as compared to the $20 \mathrm{wt} \%$, suggesting that there was faster utilization of sulfur when the additional sucrose palmitate was incorporated into the formulation (Fig. S5). Interestingly, we also found that the components of $A$. ferrooxidans cell lysate were sufficient for dispersion and enabled elemental sulfur oxidation before ferrous iron oxidation (Fig. S5).

We further characterized the aerobic ferric iron reduction that was potentially detected with growth on high concentrations of dispersed sulfur. To minimize the effects of ferrous iron oxidation by the cells, the ferrous iron was replaced with ferric iron, so that the metabolic energy for growth would have to come from the oxidation of d-sulfur. In the abiotic controls, we found that the d-sulfur itself results in some reduction of ferric iron, and is a primary contributor of the ferrous iron measured initially (Fig. 3). In the cultures with A. ferrooxidans, some additional ferrous iron than the control is measured for the first $40 \mathrm{~h}$ as the cells oxidize the d-sulfur, but a major portion of ferric iron reduction is observed as the cultures became more acidic below the $\mathrm{pH}$ threshold of 1.3. Over a third of the initial ferric iron in solution was reduced by 168 $\mathrm{h}$ when the $\mathrm{pH}$ dropped to the acid tolerance limit of $A$. ferrooxidans (Fig. 3 ). These data emphasize the observation that ferric reduction behavior continues until cell growth is inhibited by the extremely low $\mathrm{pH}$.

\section{Compatibility of lig-sulfur with genetic techniques and engineered strains}

We evaluated the effect of selective pressure on strain isolation and maintenance as an application of the media formulated with lig-sulfur. Under a mock selection scheme where AF-GFP cells, which harbor the pJRD plasmid expressing codon-optimized green fluorescent protein (GFP) under the constitutive tac promoter, were diluted hundred-fold with wild-type (WT) cells simulating the loss of the IncQ plasmid. Negligible enrichment of GFP fluorescence was observed over three passages in AFM1 media compared to pure AF-GFP even when kanamycin was present, confirming that iron accelerates the decomposition of aminoglycosides at low $\mathrm{pH}$ (Fig. 4A, 4B). When the energy source was switched from ferrous iron to lig-sulfur at $\mathrm{pH} \mathrm{1.8,} \mathrm{an}$ increase in GFP fluorescence was observed over three passages, suggesting that effective selective pressure by the antibiotic was applied over time (Fig. 4C). By increasing this sulfur-based media to an initial $\mathrm{pH}$ of 5.0, the kanamycin was more effective for selection. Increases in fluorescence, similar in level to that of 
pure AF-GFP, were seen after the first passage (Fig. 4D). Moreover, our data shows that pure AF-GFP cells grown in LSM4 at either $\mathrm{pH}$ value had a higher average median fluorescence intensity (MFI) than those grown in AFM1(K) (Fig. 5).

\section{Discussion}

Acidithiobacillus ferrooxidans has been shown to exhibit diauxic growth where the cells prefer to oxidize ferrous iron before sulfur when both substrates are available (Ponce et al., 2012). In this study, we show that ferrous iron oxidation precedes the oxidation of untreated elemental sulfur largely due to the saturation of the sulfur surface available for cell adsorption. At high cell loadings, exceeding the adsorption capacity of the sulfur particle surface, sufficient cells remain planktonic so that ferrous iron is consumed rapidly, long before sulfur oxidation is apparent. However, at lower cell loadings, the adsorption process dominates the macroscopic behavior. The oxidation of ferrous iron is delayed until there are sufficient planktonic cells. Therefore, this observed diauxic behavior can be explained through the separation of the total cell population into planktonic and non-planktonic parts. Our experiments altering iron concentration with c-sulfur suggest that iron could affect acid tolerance in these cells. The behavior observed where lower concentrations of iron led to an earlier slowdown in the acidification of the media in late exponential phase could be influenced by the ferric uptake (fur) regulator which has been found to affect extreme acid resistance in $A$. caldus, warranting further studies on the effects of fur in A. ferrooxidans as well (Chen et al., 2020). As ferric iron reduction was associated with cultures in which the media acidified the quickest, the redox state of iron could be affecting the acid stress response in these bacteria.

We then examined the role of the hydrophobicity of the sulfur particles on the bioavailability of this energy source. For A. ferrooxidans, the consumption of elemental sulfur is limited by the need to make sulfur less hydrophobic for oxidation via the deposition of EPS and possibly other secreted molecules (Gehrke et al., 1998). We discovered that sulfur likely formulated for agricultural purposes, d-sulfur, avoids the toxicity issues encountered with other surfactants and allows $A$. ferrooxidans to display a new phenotype where sulfur oxidation largely precedes that of iron oxidation. A simple method to pre-disperse sulfur particles into a dry formulation was used to demonstrate that that this newly found growth pattern could be reliably recapitulated. In this study, we found that calcium lignosulfonate to function as the best surfactant at 20 wt \%. The lignosulfonate could be acting surfactant and forming micelles around sulfur particles to allow them to mix with aqueous solution (Qiu, Kong, Zhou, \& Yang, 2010). Furthermore, the use of lignosulfonate has the added benefit of being an inexpensive and underutilized material should the rapid growth of $A$. ferrooxidans be needed at the industrial scale, as only 1-2\% of the lignin produced globally is used for valueadded products (Aro \& Fatehi, 2017). As a wide variety of chemical compounds were shown to improve sulfur utilization, these results suggest biocompatibility of the dispersant with the bacteria to be important. As cell lysate could also disperse sulfur to enable quick sulfur oxidation, this result provides an explanation for why some sulfur oxidation occurred quickly resulting in the lower maximum $\mathrm{pH}$ values measured for the cultures containing both ferrous iron and c-sulfur at the high initial cell density. While cell lysate would likely be most biocompatible for sulfur dispersion, this formulation is inefficient to produce, ruling out its use on at larger scales. Thus, the chemical method was sufficient to replace the secreted molecules $A$. ferrooxidans produces to activate sulfur particles. Overall, by dispersing the sulfur into an aqueous mixture and reducing its hydrophobic properties to prevent phase separation, the sulfur formulation becomes more bioavailable for A. ferrooxidans to oxidize quickly.

Increasing amounts of d-sulfur or lig-sulfur in the medium resulted in acidification below which ferrous iron oxidation was possible. Under conditions where the $\mathrm{pH}$ fell below the critical point of roughly 1.3, additional sulfur oxidation was seemingly accompanied by the aerobic reduction of ferric iron. Furthermore, re-oxidation of ferrous iron initially produced above this critical $\mathrm{pH}$ seemed to be negligible with the use of d-sulfur (Fig. 3). The mesophilic Acidithiobacillusspecies has been shown before to reduce small amounts of ferric iron to ferrous iron when cells are cultured aerobically below $\mathrm{pH}$ of 1.3 with untreated sulfur, similar in properties to c-sulfur, over the time span of months (Johnson, Hedrich, \& Pakostova, 2017; Sand, 1989). This reduction reaction had also been observed before under anaerobic conditions where ferric iron serves as the terminal 
electron acceptor for sulfur oxidation (Ohmura, Sasaki, Matsumoto, \& Saiki, 2002; Osorio et al., 2013; Pronk, De Bruyn, Bos, \& Kuenen, 1992). By improving the bioavailability of sulfur enabled the aerobic ferric iron reduction phenotype to be detected rapidly. Using available information about the enzymes involved with the iron and sulfur pathways under anaerobic growth, we can hypothesize a similar enzymatic pathway to explain the observed ferric iron reduction behavior (Kucera et al., 2020). In extremely acidic conditions where the ferrous iron oxidation pathway is inhibited, some of the electrons obtained from sulfur oxidation flow downhill through the forward-acting $\mathrm{bc}_{1}$ complex to ferric iron as a terminal electron acceptor (Chao, Wang, Xiao, \& Liu, 2008; Kucera, Pakostova, Lochman, Janiczek, \& Mandl, 2016; Osorio et al., 2013). Since A. ferrooxidans is unable to oxidize ferrous iron below $\mathrm{pH} 1.3$, but can continue to oxidize sulfur, either the cytochrome $\mathrm{c}_{4}$ (cycA2) or the terminal aa 3 oxidase responsible for oxygen reduction is inhibited by extremely low $\mathrm{pH}$. As A. ferrooxidans is considered a generalist bacterium in the environment, the reduction of ferric iron could be an adaptation to relieve inhibition by high redox potentials and to improve growth conditions for oxidizing sulfur (Esparza, Jedlicki, González, Dopson, \& Holmes, 2019; Kawabe, Inoue, Suto, \& Chida, 2003; Li, West, \& Banta, 2016; Smith \& Johnson, 2018). Therefore, ferric iron reduction capability seems to be driven by $\mathrm{pH}$ as well as oxygen availability.

Given this holistic understanding of $A$. ferrooxidans, we are able synthesize a unified scheme that can describe the population behavior of the cells when provided ferrous iron and sulfur in the context of $\mathrm{pH}$, percentage of planktonic cells in relation to the total population, and the hydrophobicity of the sulfur particles which we adjusted in this study (Fig. 6). The percentage of planktonic cells is dependent on the cell density and concentration of sulfur in the medium, as we have demonstrated that the cells tend to become non-planktonic given available adsorption sites on sulfur. The hydrophobicity of the sulfur particles can be controlled through the extent of dispersion using surfactants compatible with A. ferrooxidans .

Finally, we demonstrate that lig-sulfur is compatible with the genetic systems we have developed previously (Inaba et al., 2018). The use of lig-sulfur at higher $\mathrm{pH}$ allows for rapid growth of cells while maintaining selective pressure as we find that AF-GFP cells containing kanamycin resistance had a growth advantage over WT cells so that the average MFI returned to that of the pure AF-GFP culture within a few passages. This is a stark comparison to the lack of growth inhibition when these antibiotics are placed with high concentrations of iron typical for A. ferrooxidans cultivation. The average MFIs in the LSM4 media were found to be much higher than that in $\operatorname{AFM} 1(\mathrm{~K})$ media indicating that sulfur is more energetically rich and has a higher reduction potential favorable for cellular metabolism than ferrous iron alone (Bird et al., 2011; Brasseur et al., 2004).

As such, the lig-sulfur formulation demonstrated here is suitable for future synthetic biology applications with these bacteria. This discovery enabling sulfur oxidation before ferrous iron oxidation will allow for improved control of the inorganic reactions that A. ferrooxidans catalyzes.

\section{Conflict of interests}

The authors declare that the research was conducted in the absence of any commercial or financial relationships that could be construed as a potential conflict of interest.

\section{Acknowledgements}

This work was supported by the US Army Research Office (W911NF-18-1-0239), the National Science Foundation (CBET-1438263), and ARPA-E grant DE-AR0000553 from the US Department of Energy. Some of the research reported in this publication was performed in the CCTI Flow Cytometry Core, supported in part by the Office of the Director, National Institutes of Health under awards S10RR027050. The content is solely the responsibility of the authors and does not necessarily represent the official views of the National Institutes of Health. The authors have no competing interests to declare.

\section{References}

Amouric, A., Brochier-Armanet, C., Johnson, D. B., Bonnefoy, V., \& Hallberg, K. B. (2011). Phylogenetic and genetic variation among Fe(II)-oxidizing acidithiobacilli supports the view that these com- 
prise multiple species with different ferrous iron oxidation pathways.Microbiology, 157 (1), 111-122. doi:10.1099/mic.0.044537-0

Aro, T., \& Fatehi, P. (2017). Production and Application of Lignosulfonates and Sulfonated Lignin. ChemSusChem, 10 (9), 1861-1877. doi:10.1002/cssc.201700082

Beck, J. V. (1960). A ferrous-ion-oxidizing bacterium. I. Isolation and some general physiological characteristics. J Bacteriol, 79 (4), 502-509.

Bird, L. J., Bonnefoy, V., \& Newman, D. K. (2011). Bioenergetic challenges of microbial iron metabolisms. Trends Microbiol, 19 (7), 330-340. doi:10.1016/j.tim.2011.05.001

Brasseur, G., Levican, G., Bonnefoy, V., Holmes, D., Jedlicki, E., \& Lemesle-Meunier, D. (2004). Apparent redundancy of electron transfer pathways via bc1 complexes and terminal oxidases in the extremophilic chemolithoautotrophic Acidithiobacillus ferrooxidans. Biochimica et Biophysica Acta (BBA) - Bioenergetics, 1656 (2), 114-126. doi:10.1016/j.bbabio.2004.02.008

Bruscella, P., Appia-Ayme, C., Levican, G., Ratouchniak, J., Jedlicki, E., Holmes, D. S., \& Bonnefoy, V. (2007). Differential expression of two bc1 complexes in the strict acidophilic chemolithoautotrophic bacterium Acidithiobacillus ferrooxidans suggests a model for their respective roles in iron or sulfur oxidation. Microbiology, 153 (Pt 1), 102-110. doi:10.1099/mic.0.2006/000067-0

Chao, J., Wang, W., Xiao, S., \& Liu, X. (2008). Response of Acidithiobacillus ferrooxidans ATCC 23270 gene expression to acid stress. World Journal of Microbiology and Biotechnology, 24 (10), 2103-2109. doi:10.1007/s11274-008-9715-5

Chen, X.-k., Li, X.-y., Ha, Y.-f., Lin, J.-q., Liu, X.-m., Pang, X., . . . Chen, L.-x. (2020). Ferric Uptake Regulator Provides a New Strategy for Acidophile Adaptation to Acidic Ecosystems. Appl Environ Microbiol, 86 (11), e00268-00220. doi:10.1128/AEM.00268-20

Chubukov, V., Gerosa, L., Kochanowski, K., \& Sauer, U. (2014). Coordination of microbial metabolism. Nature Reviews Microbiology, 12 (5), 327-340. doi:10.1038/nrmicro3238

DiSpirito, A. A., Dugan, P. R., \& Tuovinen, O. H. (1983). Sorption of Thiobacillus ferrooxidans to particulate material. Biotechnology and Bioengineering, 25 (4), 1163-1168. doi:10.1002/bit.260250422

Eller, J. C., \& Person, J. T. (1969). US Patent No. 3461080A. U. S. P. a. T. Office.

Esparza, M., Jedlicki, E., Gonzalez, C., Dopson, M., \& Holmes, D. S. (2019). Effect of CO2 Concentration on Uptake and Assimilation of Inorganic Carbon in the Extreme Acidophile Acidithiobacillus ferrooxidans. Frontiers in Microbiology, 10 (603). doi:10.3389/fmicb.2019.00603

Espejo, R. T., Escobar, B., Jedlicki, E., Uribe, P., \& Badilla-Ohlbaum, R. (1988). Oxidation of Ferrous Iron and Elemental Sulfur by Thiobacillus ferrooxidans. Appl Environ Microbiol, 54 (7), 1694-1699.

Espejo, R. T., \& Romero, P. (1987). Growth of Thiobacillus ferrooxidans on Elemental Sulfur. Appl Environ Microbiol, 53 (8), 1907-1912.

Falagan, C., \& Johnson, D. B. (2016). Acidithiobacillus ferriphilus sp. nov., a facultatively anaerobic iron- and sulfur-metabolizing extreme acidophile. International Journal of Systematic and Evolutionary Microbiology, 66 (1), 206-211. doi:10.1099/ijsem.0.000698

Frederick, L. R., Jones, G. E., \& Starkey, R. L. (1956). Effects of medium agitation and wetting agents on oxidation of sulphur by Thiobacillus thiooxidans. J Gen Microbiol, 15 (2), 329-334. doi:10.1099/00221287$15-2-329$

Gehrke, T., Telegdi, J., Thierry, D., \& Sand, W. (1998). Importance of Extracellular Polymeric Substances from Thiobacillus ferrooxidansfor Bioleaching. Appl Environ Microbiol, 64 (7), 2743-2747. doi:10.1128/AEM.64.7.2743-2747.1998 
Ghosh, W., \& Dam, B. (2009). Biochemistry and molecular biology of lithotrophic sulfur oxidation by taxonomically and ecologically diverse bacteria and archaea. FEMS Microbiol Rev, 33 (6), 999-1043. doi:10.1111/j.1574-6976.2009.00187.x

Gumulya, Y., Boxall, N., Khaleque, H., Santala, V., Carlson, R., \& Kaksonen, A. (2018). In a quest for engineering acidophiles for biomining applications: challenges and opportunities. Genes, 9 (2), 116.

Hallberg, K. B., Gonzalez-Toril, E., \& Johnson, D. B. (2010). Acidithiobacillus ferrivorans, sp. nov.; facultatively anaerobic, psychrotolerant iron-, and sulfur-oxidizing acidophiles isolated from metal mineimpacted environments. Extremophiles, 14 (1), 9-19. doi:10.1007/s00792-009-0282-y

He, H., Xia, J.-l., Huang, G.-h., Jiang, H.-C., Tao, X.-X., Zhao, Y.-D., \& He, W. (2011). Analysis of the elemental sulfur bio-oxidation by Acidithiobacillus ferrooxidans with sulfur K-edge XANES. World Journal of Microbiology and Biotechnology, 27 (8), 1927-1931. doi:10.1007/s11274-010-0629-7

Hedrich, S., \& Johnson, D. B. (2013). Acidithiobacillus ferridurans sp. nov., an acidophilic iron-, sulfurand hydrogen-metabolizing chemolithotrophic gammaproteobacterium. International Journal of Systematic and Evolutionary Microbiology, 63 (Pt_11), 4018-4025. doi:10.1099/ijs.0.049759-0

Inaba, Y., Banerjee, I., Kernan, T., \& Banta, S. (2018). Transposase-Mediated Chromosomal Integration of Exogenous Genes inAcidithiobacillus ferrooxidans . Appl Environ Microbiol, 84 (21), e01381-01318. doi:10.1128/aem.01381-18

Johnson, D. B., Hedrich, S., \& Pakostova, E. (2017). Indirect Redox Transformations of Iron, Copper, and Chromium Catalyzed by Extremely Acidophilic Bacteria. Frontiers in Microbiology, 8 (211). doi:10.3389/fmicb.2017.00211

Kawabe, Y., Inoue, C., Suto, K., \& Chida, T. (2003). Inhibitory effect of high concentrations of ferric ions on the activity of Acidithiobacillus ferrooxidans. Journal of Bioscience and Bioengineering, 96 (4), 375-379. doi:10.1016/S1389-1723(03)90140-X

Kelly, D. P., \& Wood, A. P. (2000). Reclassification of some species of Thiobacillus to the newly designated genera Acidithiobacillus gen. nov., Halothiobacillus gen. nov. and Thermithiobacillus gen. nov. International Journal of Systematic and Evolutionary Microbiology, 50 (2), 511-516. doi:10.1099/00207713-50-2-511

Kernan, T., Majumdar, S., Li, X., Guan, J., West, A. C., \& Banta, S. (2016). Engineering the iron-oxidizing chemolithoautotrophAcidithiobacillus ferrooxidans for biochemical production.Biotechnol Bioeng, 113 (1), 189-197. doi:10.1002/bit.25703

Knickerbocker, C., Nordstrom, D. K., \& Southam, G. (2000). The role of "blebbing" in overcoming the hydrophobic barrier during biooxidation of elemental sulfur by Thiobacillus thiooxidans. Chemical Geology, 169 (3), 425-433. doi:10.1016/S0009-2541(00)00221-7

Konishi, Y., Takasaka, Y., \& Asai, S. (1994). Kinetics of growth and elemental sulfur oxidation in batch culture of thiobacillus ferrooxidans. Biotechnology and Bioengineering, 44 (6), 667-673. doi:10.1002/bit.260440602

Kucera, J., Bouchal, P., Lochman, J., Potesil, D., Janiczek, O., Zdrahal, Z., \& Mandl, M. (2013). Ferrous iron oxidation by sulfur-oxidizing Acidithiobacillus ferrooxidans and analysis of the process at the levels of transcription and protein synthesis.Antonie van Leeuwenhoek, 103 (4), 905-919. doi:10.1007/s10482-0129872-2

Kucera, J., Lochman, J., Bouchal, P., Pakostova, E., Mikulasek, K., Hedrich, S., . . . Johnson, D. B. (2020). A Model of Aerobic and Anaerobic Metabolism of Hydrogen in the Extremophile Acidithiobacillus ferrooxidans. Frontiers in Microbiology, 11 (3003). doi:10.3389/fmicb.2020.610836

Kucera, J., Pakostova, E., Lochman, J., Janiczek, O., \& Mandl, M. (2016). Are there multiple mechanisms of anaerobic sulfur oxidation with ferric iron in Acidithiobacillus ferrooxidans? Research in Microbiology, 
167 (5), 357-366. doi:10.1016/j.resmic.2016.02.004

Kucera, J., Sedo, O., Potesil, D., Janiczek, O., Zdrahal, Z., \& Mandl, M. (2016). Comparative proteomic analysis of sulfur-oxidizing Acidithiobacillus ferrooxidans CCM 4253 cultures having lost the ability to couple anaerobic elemental sulfur oxidation with ferric iron reduction. Research in Microbiology, 167 (7), 587-594. doi:10.1016/j.resmic.2016.06.009

Li, X., West, A. C., \& Banta, S. (2016). Enhancing isobutyric acid production from engineered Acidithiobacillus ferrooxidans cells via media optimization. Biotechnol Bioeng, 113 (4), 790-796. doi:10.1002/bit.25837

Liu, Z., Borne, F., Ratouchniak, J., \& Bonnefoy, V. (2001). Genetic transfer of IncP, IncQ and IncW plasmids to four Thiobacillus ferrooxidans strains by conjugation. Hydrometallurgy, 59 (2), 339-345. doi:10.1016/S0304-386X(00)00176-6

Monod, J. (1949). The Growth of Bacterial Cultures. Annual Review of Microbiology, 3 (1), 371-394. doi:10.1146/annurev.mi.03.100149.002103

Narang, A., \& Pilyugin, S. S. (2007). Bacterial gene regulation in diauxic and non-diauxic growth. Journal of Theoretical Biology, 244 (2), 326-348. doi:10.1016/j.jtbi.2006.08.007

Norris, P. R., Falagan, C., Moya-Beltran, A., Castro, M., Quatrini, R., \& Johnson, D. B. (2020). Acidithiobacillus ferrianus sp. nov.: an ancestral extremely acidophilic and facultatively anaerobic chemolithoautotroph. Extremophiles, 24 (2), 329-337. doi:10.1007/s00792-020-01157-1

Ohmura, N., Sasaki, K., Matsumoto, N., \& Saiki, H. (2002). Anaerobic Respiration Using Fe3+, S0, and H2 in the Chemolithoautotrophic Bacterium Acidithiobacillus ferrooxidans. J Bacteriol, 184 (8), 2081. doi:10.1128/JB.184.8.2081-2087.2002

Okano, H., Hermsen, R., Kochanowski, K., \& Hwa, T. (2020). Regulation underlying hierarchical and simultaneous utilization of carbon substrates by flux sensors in Escherichia coli. Nature Microbiology, 5 (1), 206-215. doi:10.1038/s41564-019-0610-7

Osorio, H., Mangold, S., Denis, Y., Nancucheo, I., Esparza, M., Johnson, D. B., . . . Holmes, D. S. (2013). Anaerobic sulfur metabolism coupled to dissimilatory iron reduction in the extremophile Acidithiobacillus ferrooxidans. Appl Environ Microbiol, 79 (7), 2172-2181. doi:10.1128/AEM.03057-12

Peng, A.-a., Liu, H.-c., Nie, Z.-y., \& Xia, J.-l. (2012). Effect of surfactant Tween-80 on sulfur oxidation and expression of sulfur metabolism relevant genes of Acidithiobacillus ferrooxidans. Transactions of Nonferrous Metals Society of China, 22 (12), 3147-3155. doi:10.1016/S1003-6326(12)61767-1

Peng, J.-B., Yan, W.-M., \& Bao, X.-Z. (1994). Solid Medium for the Genetic Manipulation of Thiobacillus ferrooxidans. The Journal of General and Applied Microbiology, 40 (3), 243-253. doi:10.2323/jgam.40.243

Ponce, J. S., Moinier, D., Byrne, D., Amouric, A., \& Bonnefoy, V. (2012). Acidithiobacillus ferrooxidans oxidizes ferrous iron before sulfur likely through transcriptional regulation by the global redox responding RegBA signal transducing system. Hydrometallurgy, 127-128 , 187-194. doi:10.1016/j.hydromet.2012.07.016

Pronk, J. T., de Bruyn, J. C., Bos, P., \& Kuenen, J. G. (1992). Anaerobic Growth of Thiobacillus ferrooxidans. Appl Environ Microbiol, 58 (7), 2227-2230.

Qiu, X., Kong, Q., Zhou, M., \& Yang, D. (2010). Aggregation Behavior of Sodium Lignosulfonate in Water Solution. The Journal of Physical Chemistry B, 114 (48), 15857-15861. doi:10.1021/jp107036m

Quatrini, R., Appia-Ayme, C., Denis, Y., Jedlicki, E., Holmes, D. S., \& Bonnefoy, V. (2009). Extending the models for iron and sulfur oxidation in the extreme acidophile Acidithiobacillus ferrooxidans .BMC Genomics, 10 , 394. doi:10.1186/1471-2164-10-394

Ramirez, P., Guiliani, N., Valenzuela, L., Beard, S., \& Jerez, C. A. (2004). Differential protein expression during growth of Acidithiobacillus ferrooxidans on ferrous iron, sulfur compounds, or metal sulfides. Appl 
Environ Microbiol, 70 (8), 4491-4498. doi:10.1128/aem.70.8.4491-4498.2004

Sand, W. (1989). Ferric Iron Reduction by Thiobacillus ferrooxidans at Extremely Low pH-Values. Biogeochemistry, 7 (3), 195-201. doi:10.1007/BF00004217

Smith, S. L., \& Johnson, D. B. (2018). Growth of Leptospirillum ferriphilum in sulfur medium in coculture with Acidithiobacillus caldus. Extremophiles : life under extreme conditions, 22 (2), 327-333. doi:10.1007/s00792-018-1001-3

Suzuki, I., Takeuchi, T. L., Yuthasastrakosol, T. D., \& Oh, J. K. (1990). Ferrous Iron and Sulfur Oxidation and Ferric Iron Reduction Activities of Thiobacillus ferrooxidans Are Affected by Growth on Ferrous Iron, Sulfur, or a Sulfide Ore. Appl Environ Microbiol, 56 (6), 1620-1626.

Valdes, J., Pedroso, I., Quatrini, R., Dodson, R. J., Tettelin, H., Blake, R., 2nd, . . . Holmes, D. S. (2008). Acidithiobacillus ferrooxidans metabolism: from genome sequence to industrial applications. BMC Genomics, 9 , 597. doi:10.1186/1471-2164-9-597

Wang, H., Liu, X., Liu, S., Yu, Y., Lin, J., Lin, J., . . . Zhao, J. (2012). Development of a markerless gene replacement system for Acidithiobacillus ferrooxidans and construction of a pfkB mutant.Appl Environ Microbiol, 78 (6), 1826-1835. doi:10.1128/AEM.07230-11

Wang, R., Lin, C., Lin, J., Pang, X., Liu, X., Zhang, C., . . . Chen, L. (2017). Construction of novel pJRD215-derived plasmids using chloramphenicol acetyltransferase (cat) gene as a selection marker for Acidithiobacillus caldus. PLOS ONE, 12 (8), e0183307. doi:10.1371/journal.pone.0183307

Wong, P., Gladney, S., \& Keasling, J. D. (1997). Mathematical Model of the lac Operon: Inducer Exclusion, Catabolite Repression, and Diauxic Growth on Glucose and Lactose. Biotechnology Progress, 13 (2), 132143. doi:10.1021/bp970003o

Wu, L., Yang, B., Wang, X., Wu, B., He, W., Gan, M., . . . Wang, J. (2019). Effects of Single and Mixed Energy Sources on Intracellular Nanoparticles Synthesized by Acidithiobacillus ferrooxidans.Minerals, 9 (3), 163.

Xia, L.-X., Shen, Z., Vargas, T., Sun, W.-J., Ruan, R.-M., Xie, Z.-D., \& Qiu, G.-Z. (2013). Attachment of Acidithiobacillus ferrooxidans onto different solid substrates and fitting through Langmuir and Freundlich equations. Biotechnology Letters, 35 (12), 2129-2136. doi:10.1007/s10529-013-1316-1

Yarzabal, A., Appia-Ayme, C., Ratouchniak, J., \& Bonnefoy, V. (2004). Regulation of the expression of the Acidithiobacillus ferrooxidans rus operon encoding two cytochromes c, a cytochrome oxidase and rusticyanin. Microbiology, 150 (Pt 7), 2113-2123. doi:10.1099/mic.0.26966-0

Yu, Y., Liu, X., Wang, H., Li, X., \& Lin, J. (2014). Construction and characterization of tetH overexpression and knockout strains of Acidithiobacillus ferrooxidans . J Bacteriol, 196 (12), 2255-2264. doi:10.1128/JB.01472-13

Zhang, Y., Yang, Y., Liu, J., \& Qiu, G. (2013). Isolation and characterization of Acidithiobacillus ferrooxidans strain QXS-1 capable of unusual ferrous iron and sulfur utilization. Hydrometallurgy, 136 , 51-57. doi:10.1016/j.hydromet.2013.03.005

\section{Figure Legends}

Fig. 1. Onset of iron oxidation is influenced strongly by initial cell density and presence of sulfur. (A) The ferrous iron oxidation (gray, unfilled) and $\mathrm{pH}$ (light blue, unfilled) in the absence of c-sulfur, and the effect of adding $10 \mathrm{~g} / \mathrm{L}$ c-sulfur to AFM1 medium on ferrous iron consumption (black, filled) and $\mathrm{pH}$ (blue, filled) is shown. Squares, diamonds, and triangles indicate the three experimental replicates. The initial cell density was $\mathrm{OD}_{600}$ of 0.05 . (B) shows the same data with an initial cell density of $\mathrm{OD}_{600}$ of 0.005 . The culture highlighted in the red line is shown in (D). (C) Time course data of ferrous iron consumption in AFM1 medium with varying concentrations of iron (72 mM, orange squares; $1 \mathrm{mM}$, gray triangles; 100 
$\mu \mathrm{M}$ blue diamonds; no iron, yellow crosses; no iron and abiotic, green circles) and $10 \mathrm{~g} / \mathrm{L}$ c-sulfur. The initial cell density was $\mathrm{OD}_{600}$ of 0.001 for biotic cultures. After consumption of the ferrous iron, sulfur oxidation continues until $\mathrm{pH} 1.3$ where ferric iron reduction activity can be measured through an increase in ferrous iron concentration. (D) Images showing the changes in the appearance of c-sulfur and medium over time. The data displayed for (A, B) are all measurements taken from three independent cultures for each condition. Data for $(\mathrm{C})$ represent mean measurements taken from three independent cultures, and the error bars represent the SD. Many error bars are smaller than the size of the symbols.

Fig. 2. The dispersion of sulfur affects bioavailability changes substrate utilization behavior in A. ferrooxidans . (A) Time course data of ferrous iron consumption (black) and $\mathrm{pH}$ (blue) in AFM1 medium with $1 \mathrm{~g} / \mathrm{L}$ c-sulfur (squares) or d-sulfur (diamonds). (B) Time course data showing the effect of d-sulfur concentration on ferrous iron oxidation (black, top) and $\mathrm{pH}$ (blue, bottom) in AFM1 medium with $10 \mathrm{~g} / \mathrm{L}$ (squares), 5 $\mathrm{g} / \mathrm{L}$ (diamonds), $2.5 \mathrm{~g} / \mathrm{L}$ (triangles), $2 \mathrm{~g} / \mathrm{L}$ (crosses), or $1 \mathrm{~g} / \mathrm{L}$ (circles; same data as diamonds in (A). (C) Time course data demonstrating that growth in AFM1 medium with lig-sulfur displays similar behavior to d-sulfur using a concentration of $10 \mathrm{~g} / \mathrm{L}$ (squares) or $1 \mathrm{~g} / \mathrm{L}$ (circles). An initial cell density, $\mathrm{OD}_{600}$ of 0.005 , of $A$. ferrooxidanswas used for all cultures. For (A, B, C), data represent mean measurements taken from three independent cultures, and the error bars represent the SD. Many error bars are smaller than the size of the symbols.

Fig. 3. Dispersed sulfur enables rapid acidification of media to induce ferric iron reduction. Time course data demonstrating ferric iron reduction with $10 \mathrm{~g} / \mathrm{L}$ d-sulfur in AFM1 medium containing $72 \mathrm{mM}$ ferric iron. The abiotic condition is shown in black and the biotic condition is shown in green with the change in $\mathrm{pH}$ (squares) and ferrous iron (circles) shown. The initial cell density was $\mathrm{OD}_{600}$ of 0.005 for biotic cultures. Data represent means using measurements taken from three independent cultures, and the error bars represent the SD. Many error bars are smaller than the size of the symbols.

Fig. 4. Selective pressure from kanamycin is maintained during growth on lig-sulfur from a high $\mathrm{pH}$ with small amounts of iron. (A, B, C, D) Histograms of GFP fluorescence over three passages (green, AF-GFP control; pale blue, 1st; sky blue, 2nd; blue, 3rd) in various media using an initial cell composition of AFGFP cells and WT in a 1:100 ratio and initial cell density of OD600 of 0.005. After each passage, cells were diluted hundred-fold into fresh medium for the next passage. (A) Passages in AFM1 medium. (B) Passages in AFM1 medium with kanamycin. (C) Passages in LSM4 medium (initial pH 1.8) with kanamycin. (D) Passages in LSM4 medium (initial pH 5.0) with kanamycin. $250 \mu \mathrm{g} / \mathrm{mL}$ kanamycin sulfate were used for (B, C, D). The data shown represents all gated events.

Fig. 5. Average MFI values for thrice passaged mixtures of WT and AF-GFP against pure cultures of AFGFP. The MFIs of GFP fluorescence were averaged from the histograms shown in Fig. 4. Data represent means using measurements taken from three histograms, and the error bars represent the SD.

Fig. 6. The population behavior of A. ferrooxidans when provided ferrous iron and/or sulfur for metabolic energy can be described by knowing the $\mathrm{pH}$, percentage of planktonic cells in relation to the total population, and the hydrophobicity of the sulfur. The larger markers correspond to relatively higher activity per cell and the smaller markers correspond to relatively lower activity per cell in each of the given regions. Marker $\mathrm{Z}$ is unshaded as no growth was observed with the reported conditions. (A-J) Markers refer to conditions described in this study. (V-Z) Markers refer to conditions estimated from methods and data provided in other studies. (A) AFM1 medium with initial $\mathrm{OD}_{600}$ of 0.05 at inoculation (Fig. 1A). (B) AFM1 medium with initial $\mathrm{OD}_{600}$ of 0.005 at inoculation (Fig. 1B). (C) AFM1 medium and $10 \mathrm{~g} / \mathrm{L}$ c-sulfur with initial $\mathrm{OD}_{600}$ of 0.05 at inoculation (Fig. 1A). (D) AFM1 medium and $0.75 \mathrm{~g} / \mathrm{L}$ with cell lysate sulfur with initial $\mathrm{OD}_{600}$ of 0.005 at inoculation (Fig. S5). (E) AFM1 medium and $1 \mathrm{~g} / \mathrm{L}$ d-sulfur or lig-sulfur with $\mathrm{OD}_{600}$ of initial 0.005 at inoculation (Fig. 2B, 2D). (F) AFM1 medium and $10 \mathrm{~g} / \mathrm{L}$ c-sulfur with initial $\mathrm{OD}_{600}$ of 0.005 at inoculation (Fig. 1B). (G) AFM1 medium and $10 \mathrm{~g} / \mathrm{L}$ c-sulfur with initial $\mathrm{OD}_{600}$ of 0.05 at late exponential phase (Fig. 1A). (H) AFM1 medium and $10 \mathrm{~g} / \mathrm{L}$ d-sulfur with initial $\mathrm{OD}_{600}$ of 0.005 at late exponential phase (Fig. 3B). (I) AFM1 medium and $10 \mathrm{~g} / \mathrm{L}$ c-sulfur with $\mathrm{OD}_{600}$ of 0.005 at late exponential phase (Fig. 1B). (J) LSM4 medium at initial $\mathrm{pH} 5.0$ with initial $\mathrm{OD}_{600}$ of 0.005 at inoculation. (V) $5 \mathrm{mM}$ 
ferric iron and $5 \mathrm{~g} / \mathrm{L}$ elemental sulfur initially ((Johnson et al., 2017); from Fig. 1). (W) $5 \mathrm{mM}$ ferric iron and $5 \mathrm{~g} / \mathrm{L}$ elemental sulfur at late exponential phase ((Johnson et al., 2017); from Fig. 1). (X) 9K-Fe+S medium (10 g/L elemental sulfur) with cells domesticated in 9K-Fe medium at inoculation ((Zhang, Yang, Liu, \& Qiu, 2013); from Fig. 5). (Y) Fe(II) $+\mathrm{S}^{0}$ medium (10 g/L elemental sulfur) sub-cultured in the presence of iron and sulfur at inoculation ((Ponce et al., 2012); from Fig. 2). (Z) ATCC medium 2039 adjusted to $\mathrm{pH} 1.0$ at inoculation ((Chao et al., 2008); from Fig. 2).
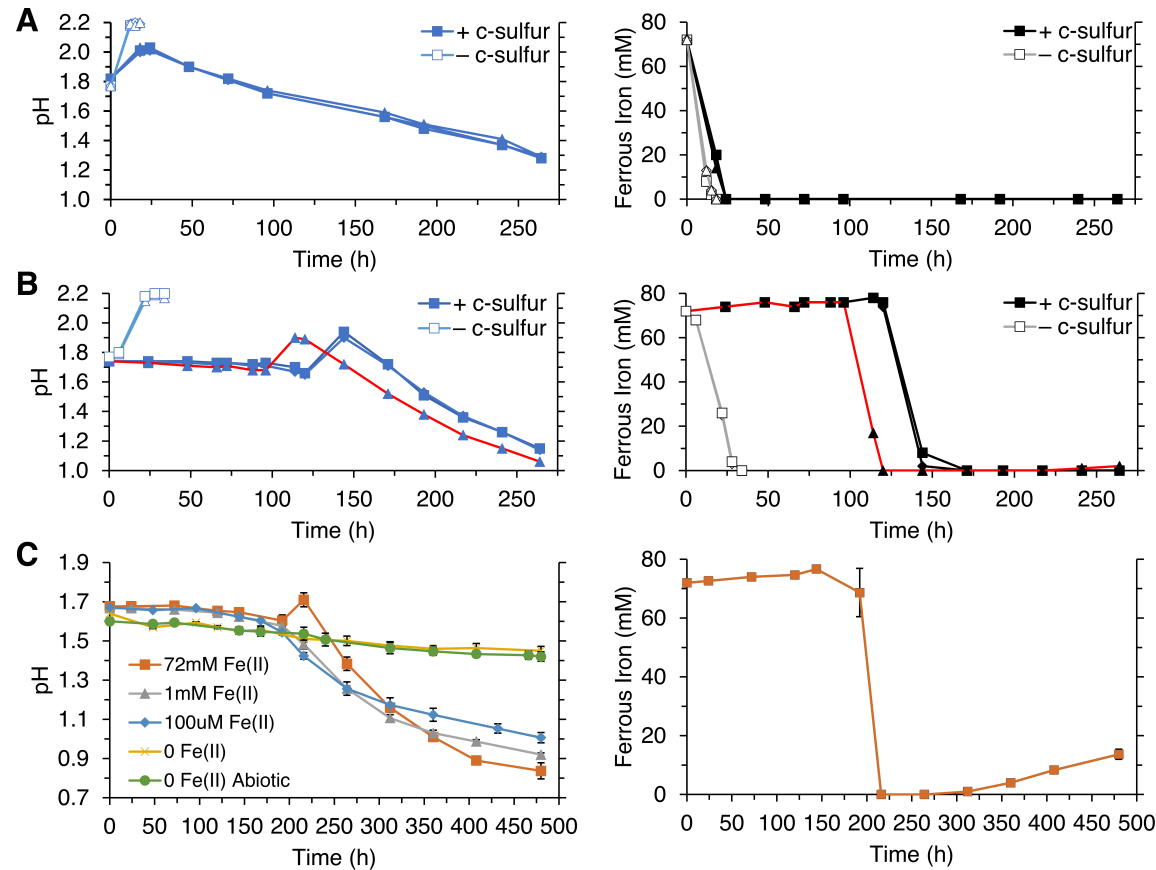

D
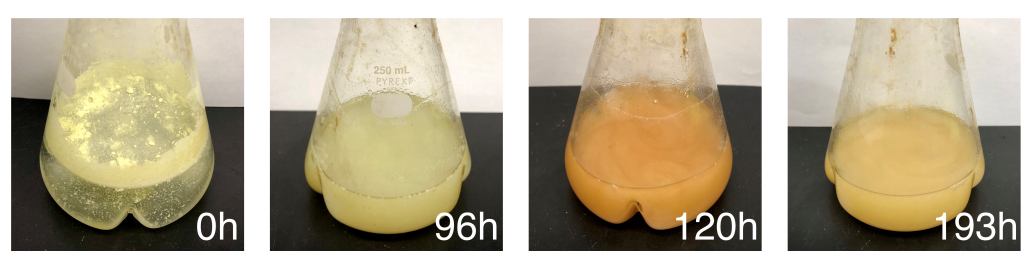

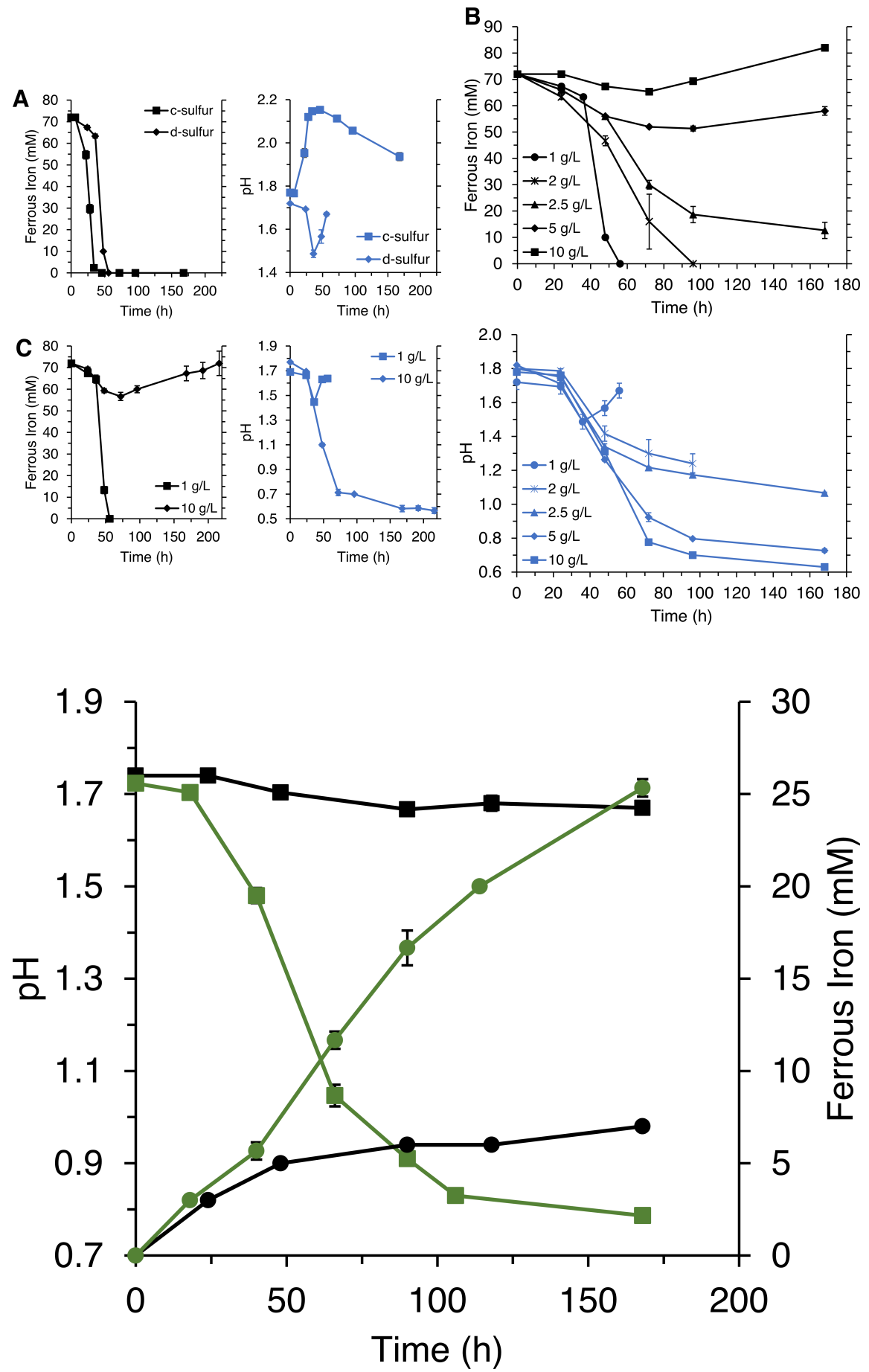
A

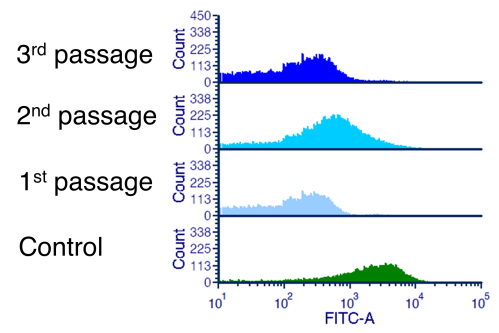

B

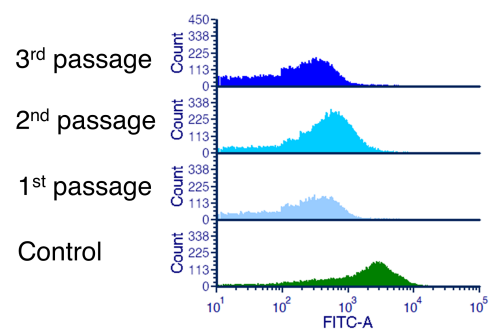

C

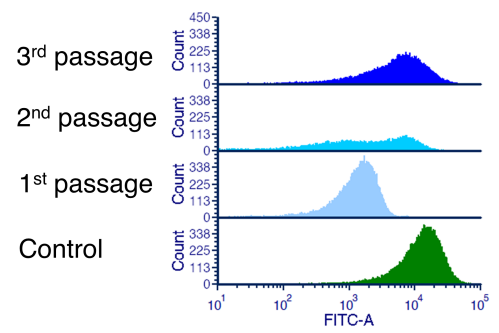

D

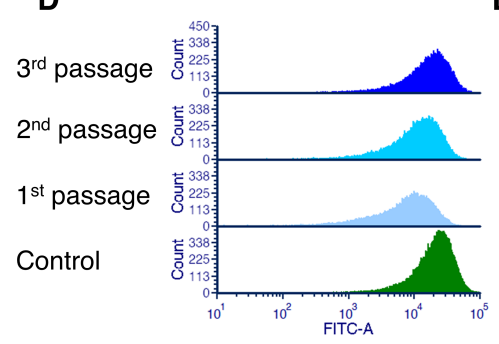

AFM1

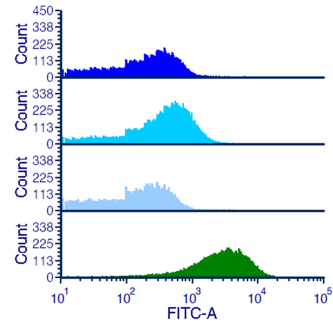

AFM1K

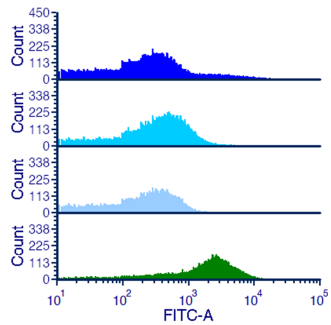

LSM4 pH 1.8
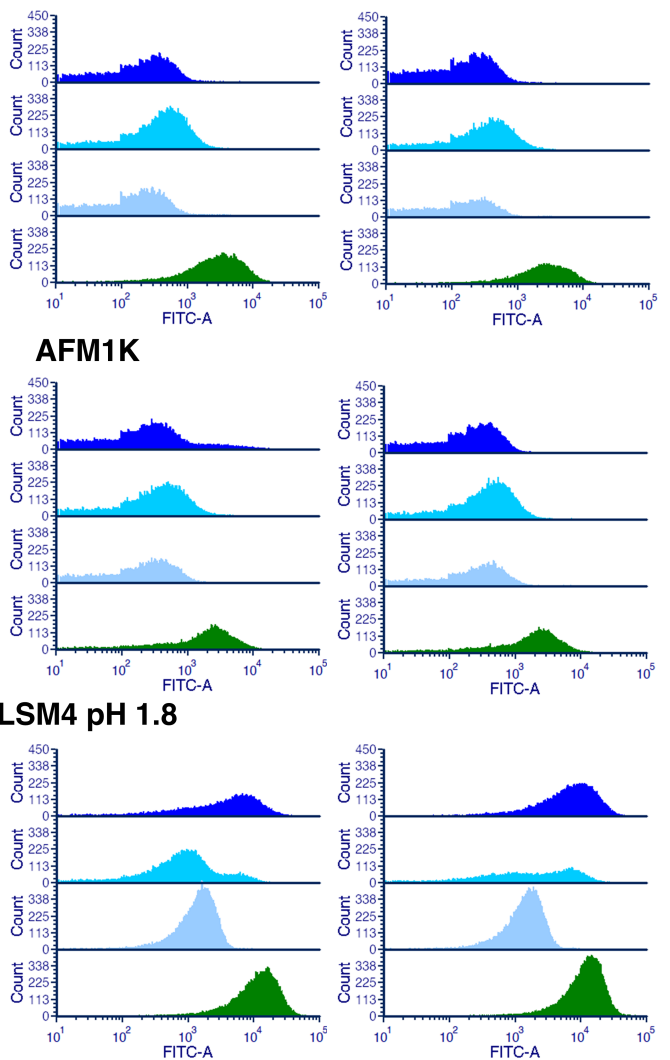

LSM4 pH 5.0
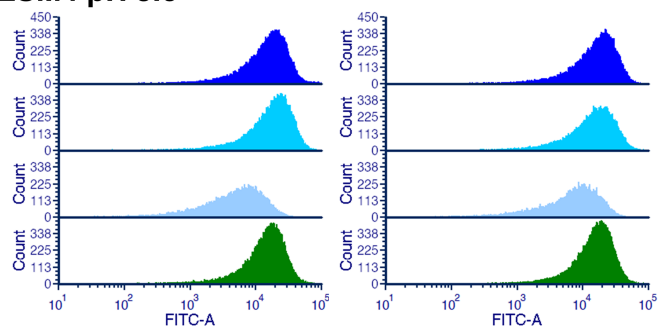

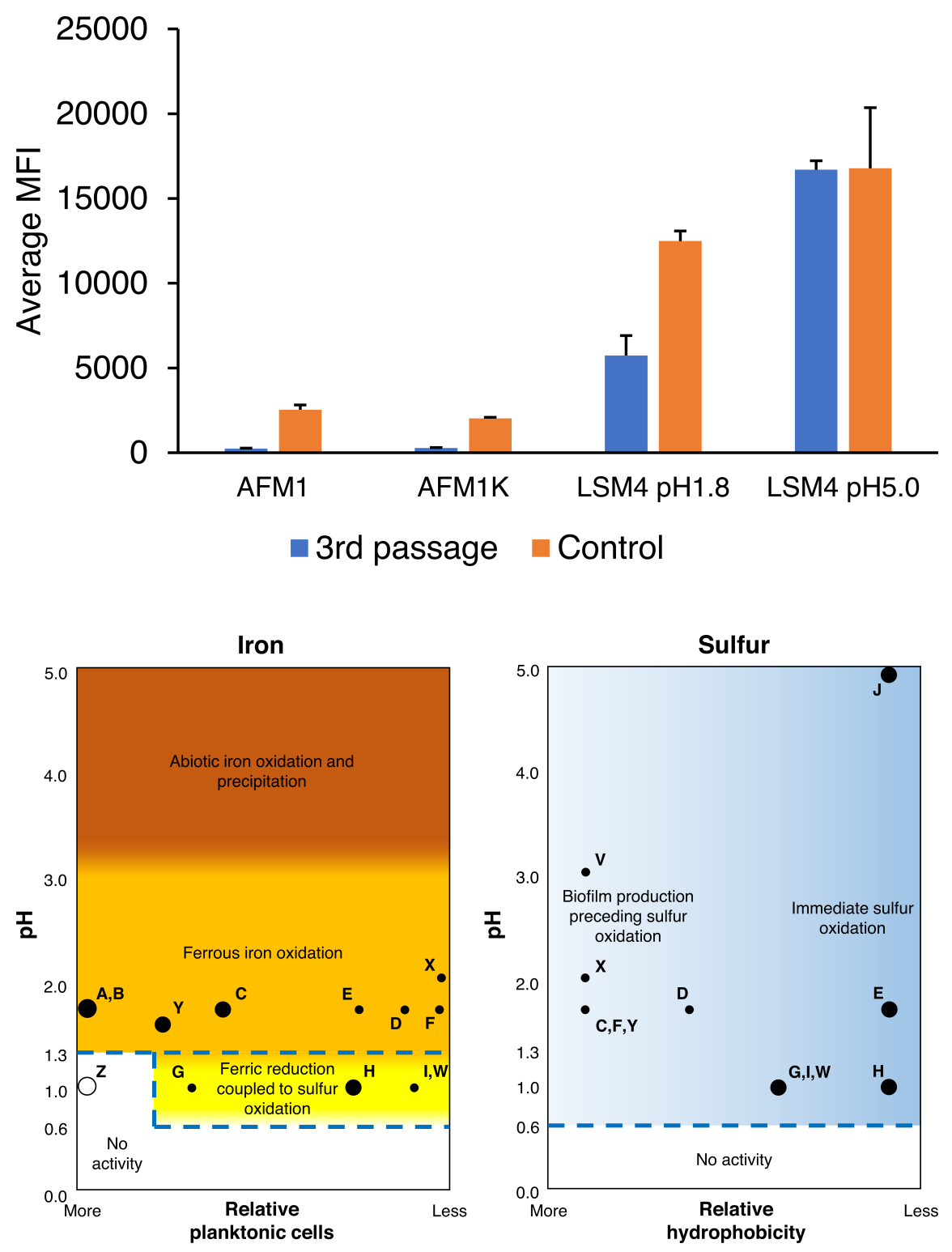